\title{
Barking Up the Wrong Tree: A Qualitative Study of the Potential for Dog-Owner Technology
}

\author{
Lynne Hall \\ University of Sunderland \\ Sunderland, UK, SR6 ODD \\ lynne.hall@sunderland.ac.uk
}

\author{
Sharon McDonald \\ University of Sunderland \\ Sunderland, UK, SR6 ODD \\ sharon.mcdonald@sunderland.ac.uk
}

\author{
Shell Young \\ University of Sunderland \\ Sunderland, UK, SR6 ODD \\ shell.young@sunderland.ac.uk
}

\begin{abstract}
Current approaches to dog technology are predominantly aimed at owners monitoring and remotely engaging their dogs to prevent boredom when they are left home alone. The potential of technology to enhance the collocated dog-human experience has received little attention. This paper discusses a qualitative study with 10 owners and their dogs, exploring how technology could be used to enhance dog-human interaction in the home. Results highlight that dog toys are actually targeted at play involving both dog and owner; that playful interactions between dogs and owners focus on increasing bonding and affective symbiosis; and that the play isn't the point for neither dog nor human, the relationship is. The study concludes that dog-human technology for collocated enjoyable interaction will be significantly different than that used in remote human-dog interaction and requires further work.
\end{abstract}

\section{Dog Technology. Dog-Computer Interaction. Dog-Owner relationship. Animal Computer Interaction}

\section{INTRODUCTION}

The engagement and companionship that is achieved through owning a dog can make a significant contribution to a humans' emotional wellbeing (McConnell et al., 2011). In 2017, there were almost 90 million dogs in over 60 million households in the USA (APPA, 2017). Dogs are continually the most popular pets in the UK where in $2017,24 \%$ of households provide a home to 8.5 million dogs (PFMA, 2017). For 95\% of dog owners, our dog is part of the family, with Mintel's survey highlighting our desire to pamper and care for our dogs, just as for any other family member, with the UK spending over $£ 10$ billion a year on their dogs alone (GroomArts Academy, 2018). Recreational spend on dogs is steadily increasing, with the average dog owning household in the UK spending £183.96 annually on Toys and Treats (PFMA, 2017).

Dog owners want to improve the quality of life for their canine companions. And so, we turn to technology, the panacea of improvement that has so radically altered many of our own experiences. Technology offerings for dogs are significantly increasing, for example wearable pet technology is projected to grow by $16 \%$ by 2020 (Technavio, 2017). Crowdfunding dog technology, such as for PlayDate highlights considerable consumer demand (Adams, 2016).
Dog-technology is increasingly aimed at the use context where the dog is in and the owner is out, with current approaches to dog technology predominantly aimed at owners monitoring and remotely engaging with their dogs. Approaches focused on the dog as user (Mancini, 2011) dominate, however, the potential of technology to enhance the collocated dog-human experience surprisingly has received little attention. Where collocated activities have been considered, this is often focused on the dog's role as co-worker (Jackson et al., 2013) or carer rather than companion (Robinson et al., 2014).

Responding to this lack of consideration of dogs with owners is the start point of our research. We are trying to understand if, and how, technology could be used to improve the collocated experience of owners and dogs. Almost no technologies nor concepts are available, with unknown unknowns characterising this novel use context. This paper discusses our approach to understanding this context, trying to frame and scope collocated dogowner technology opportunities.

To explore the potential for dog-owner technology, we initially reviewed dog technologies and research literature, identifying examples of current dog technology, as detailed in section 2. To explore current owners and dogs' interactions and potential 
for integrating technology into their lives, we developed a semi-structured interview including dogowner interaction observation and YouTube clips of existing dog technologies, as outlined in section 3. Data analysis focused on the most salient and relevant information, providing the gist of the sessions to inform future research directions with sections 4 and 5 discussing our results. Sections 6 and 7 consider our approach and main findings, discussing their use to inform current and future research targeting dogs and their owners.

\section{DOG TECHNOLOGY}

Technology has been applied in the home context to meet owner and dog's basic needs, with readily available products including LED collars, automated food dispensers and dog-doors. Beyond these utilitarian needs, dog technology offerings can be broadly categorised as:

\subsection{Where are you... Tracking devices}

Microchips are required by law in many countries, enabling dogs to be identified if they are lost. Whilst microchips are passive, tracking devices typically attached to the dog's collar can enable owners to always know where their dogs are. Trackers such as Findster (Findster Technologies, 2017) and Tractive GPS Pet Tracker (Tractive, 2017) can also monitor if the dog goes beyond the home, with perimeter settings and alerts.

\subsection{How are you... Monitoring Devices}

Some tracking technologies incorporate health and activity monitoring, enabling the owner to monitor their dog's activity levels and health (Whistle, 2017). Fitbark (Fitbark, 2017) provides the dog's 'health' profile, monitoring activity levels, quality of sleep, distance travelled, calories burned, and overall health and behaviour 24/7. So just like you, your dog can have their own quantified self, with the opportunity to share data with clinicians.

\subsection{How are you getting on... Camera Technologies}

There is considerable interest in technologies for dogs that are 'home alone' (DiGuilio, 2017) with a number of devices (e.g. Furbo (Furbo, 2017), Petzi (Petzi, 2016)) enabling the remote owner to watch, engage and interact with their dog. Livewire (Beren, 2017) identifies Petcube (Petcube, 2017) as the best pet camera and it provides the typical approach of an interactive camera enabling the owner to watch and speak to their dog, get alerts about disturbances and, most significantly for the dog, to remotely dispense treats. Reviews are typically very positive and highlight that dogs (unsurprisingly) are quick to learn and engage with the treat dispenser.

\subsection{Are you bored... Play technologies}

Whilst the treats clearly do it for the dogs, remote interaction also focuses on entertainment, on engaging the dog in fun. However, most remote interaction devices are based on the incorporation of cameras in a static device or wall-mounted with relatively little opportunity for interactive play. Whilst some camera devices offer laser games, these are primarily aimed at cats (Pawbo, 2017).

There has recently been some remote controlled toys, for example PlayDate (PlayDate, 2017) a remote-controlled ball that allows you to play with your dog remotely. GoBone (GoBone, 2018) is a remote-controlled bone, that can be interactive, with the bone moving and offering playful opportunities by phone. iFetch (iFetch, 2018) builds on the classic fetch-object with an automatic ball thrower that the dog plays with themselves.

Cleverpet (CleverPet, 2018) uses a 'keypad' providing a game-based approach for dogs where treats are provided in response to game-winning actions, based on the use of lit touch pads. The games range from the dog selecting any pad to following a longer complex sequence as pads light up. As identified in the Cleverpet videos dogs do engage and do seem to enjoy the experience. Again, this is for the dog that is home alone with the owner able to get live updates of whether the dog is engaging, resetting games levels through their mobile device.

\subsection{The Unconsidered Question - shall we do something together now?}

The majority of dog technology is either for us to monitor our dogs or for remote entertainment or engagement. However, there is a distinct lack of technology to use together with our dogs. So although many owners often spend time and interact or play with their dogs, there is remarkably little technology that aims to enhance that experience.

What technology would a dog like? Who knows? We can't easily ask the dog, with attempts to engage dogs in meaningful participatory design highlighting limitations and challenges (Mancini, 2017). However, whilst communicating with the dogs is beyond us, we do have an alternative. Beyond the dog itself, owners have the most in-depth knowledge of their dog's perspective.

From their studies of owner's dog-related consumption experiences, Dotson \& Hyatt (2008) identified 7 dimensions, three of which categorise the dog-human relationship. Firstly, a Symbiotic Relationship where there is a mutually beneficial relationship between owner and dog, with the owner affectively engaged with the dog. Secondly, the dogoriented self-concept where the dog is important to the human's self-concept and social self, with the 
dog both an extension of the self and owner's best friend. And thirdly, anthropomorphism with the dog viewed more as a person than as a dog.

Whilst (Mancini, 2017) has focused on the dogs and (Dotson \& Hyatt, 2008; Paldanius et al., 2011) on the owners, there have been few attempts to engage with owners and dogs together. In engaging with both owners and dogs our goal was to increase our understanding of the context and to gain insights and perspectives that could be used for future research and design. To achieve this, we engaged with our users 'in the wild,' with our protocol developed to take place with both dog and owner in the home, the typical place for collocation.

\section{METHOD}

\subsection{Participants}

We wanted to interview owners and their dogs in their own home environment; therefore, we used an opportunistic sampling strategy to retain ecological validity and to limit risk to the researchers. Consequently, we kick-started the interview process by utilising known contacts. Table 1 summarises the demographic details of our participating dogs and their owners. All but two of our dogs were male and we interviewed 4 male and 7 female owners.

The first six interviews (Rupert; Whiskey; Toby; Evra; Bentley and Jemma) were conducted in one dog and one owner pairs; the seventh with one owner and her three dogs (Elwyn; Pudsey and Benji); interview eight was conducted with two owners and their two dogs (Red and Murphy) and the final interview was conducted with two owners and one dog (Georgie).

Table 1: Participant Characteristics

\begin{tabular}{|c|c|c|c|}
\hline \multirow[t]{2}{*}{ Name } & \multicolumn{3}{|c|}{ Dogs and Owner Characteristics } \\
\hline & $\begin{array}{l}\text { Breed, Age, } \\
\text { Gender }\end{array}$ & Household & $\begin{array}{l}\text { Gender } \\
\text { Age }\end{array}$ \\
\hline Rupert & $\begin{array}{l}\text { Golden } \\
\text { Retriever; 12; } \\
\text { Male }\end{array}$ & Couple & $M ; 58$ \\
\hline Whiskey & $\begin{array}{l}\text { Westie; 13; } \\
\text { Male }\end{array}$ & Couple & $F ; 57$ \\
\hline Toby & $\begin{array}{l}\text { Labrador; 8; } \\
\text { Male }\end{array}$ & Couple & $M ; 48$ \\
\hline Evra & $\begin{array}{l}\text { Dachshund; } \\
\text { 3; Male }\end{array}$ & Singleton & $F ; 31$ \\
\hline Bentley & $\begin{array}{l}\text { Cavapoo; 2; } \\
\text { Male }\end{array}$ & Couple & $F ; 53$ \\
\hline Jemma & $\begin{array}{l}\text { Chow; 11; } \\
\text { Female }\end{array}$ & Singleton & $F ; 69$ \\
\hline Elwyn & $\begin{array}{l}\text { Papillon; } 6 \\
\text { months; Male }\end{array}$ & Singleton & $F ; 73$ \\
\hline Pudsey & $\begin{array}{l}\text { Papillon;5; } \\
\text { Male }\end{array}$ & Singleton & $F ; 73$ \\
\hline Benji & $\begin{array}{l}\text { Papillon; 10; } \\
\text { Male }\end{array}$ & Singleton & $F ; 73$ \\
\hline
\end{tabular}

\begin{tabular}{|l|l|l|l|}
\hline Red & $\begin{array}{l}\text { Sighthound; } \\
\text { 4; Male }\end{array}$ & Couple & $\begin{array}{l}\text { F; } 58 \\
\text { M } 62\end{array}$ \\
\hline Murphy & Sighthound; & Couple & F;58 \\
& 4; Male & & $M ; 62$ \\
\hline Georgie & Cairn Terrier; & Family incl. & F;72 \\
& 6; Female & teenagers & $M ; 17$ \\
\hline
\end{tabular}

\subsection{Interview procedure and analysis}

Talking about the dog-owner relationship is an unusual subject, to support the discussion we developed a semi-structured interview. As detailed in table 2, this covered a range of themes enabling us to gradually focus on, how could we use technology to enhance the dog-owner relationship. In addition, to gain some input from the dog, owners were asked to play and interact with their dog.

The format of our exploratory semi-structured interview included both talking to the owner and observing the dog and owner interacting with the dog. Each session was expected to last an hour, with notes and recordings taken.

Qualitative studies are often used to obtain rich data, however, here, at this exploratory stage we were attempting to gain early insights into the use context, an outline of opportunities that technology could offer potential future research and design directions. In this study, after the sessions, meaning was extracted from notes and recordings, identifying categories and patterns of answers, highlighting key areas relevant to collocated dog-owner technology. Brief illustrative comments to highlight responses to questions were provided on post-it notes. These were then arranged into an affinity diagram further refining themes and perspectives

\section{RESULTS}

During the course of each interview our respondents would revisit themes they had previously discussed. For example, when exploring theme 4 (the use of dog toys) our respondents would often revisit their dogs' motivations for engaging with their toys. Consequently, the analysis generated insights that went across themes. To facilitate the presentation of the results we, therefore, highlight which of our interview themes gave rise to the qualitative insights presented.

\subsection{Dog-owner Motivations, Interactions and Play}

This section draws insights from theme 2 (Motivations), theme 3 (Interactions and Play) and theme 4 (Dog Toys).

In terms of characterising the relationships between the owners and their dogs, all but one of our interviewees identified as having a symbiotic relationship with their dog.. Owners discussed their mutually beneficial relationship with the dog and the affective nature of this engagement. 
Table 2: Question themes Used within the Semi-Structured Interviews

\begin{tabular}{|c|c|c|}
\hline \multicolumn{2}{|r|}{ Theme } & Focus \\
\hline 1 & $\begin{array}{l}\text { Participant } \\
\text { Demographics }\end{array}$ & Owner (age, gender); Dog (age, gender, breed). Other members of household \\
\hline 2 & Motivations & $\begin{array}{l}\text { Owners were asked how long they had been a dog owner and why they owned a dog. Owners were } \\
\text { asked about what motivated and interested the dog. }\end{array}$ \\
\hline 3 & $\begin{array}{l}\text { Interactions and } \\
\text { Play }\end{array}$ & $\begin{array}{l}\text { Owners were asked about interactions with the dog, identifying types of interactions including who } \\
\text { initiates play and how, the type of games that are played, what the owner enjoys, what the owner } \\
\text { thinks the dog enjoys and how they know the dog is enjoying it. The owners were asked to contrast } \\
\text { inside and outside play and where appropriate how dogs they played with each other. }\end{array}$ \\
\hline 4 & Dog Toys & $\begin{array}{l}\text { Owners were asked if they bought dog toys and if yes, they did, what type (e.g. squeaky toys, balls, } \\
\text { chewable rubber, plush toys, tug toys, problem solving toys). Owners were asked why they bought } \\
\text { toys. }\end{array}$ \\
\hline 5 & $\begin{array}{l}\text { Voices and } \\
\text { Sounds }\end{array}$ & $\begin{array}{l}\text { Owners were asked if there were any sounds or words that interested their dog. And whether the dog } \\
\text { responded to recordings of voice and if so, how. }\end{array}$ \\
\hline 6 & Audio-Visual & $\begin{array}{l}\text { The owners were asked if they recorded their dog (or other dogs) playing and if they had ever played } \\
\text { them to their own dog and if they did, did the dog respond. Owners were asked about whether their } \\
\text { dog watched or responded to television }\end{array}$ \\
\hline 7 & $\begin{array}{l}\text { Technology for } \\
\text { dogs }\end{array}$ & $\begin{array}{l}\text { Owners were asked if they had ever come across dog toys that have a technological component. } \\
\text { They were shown three examples of technology (see table } 2 \text { for images) targeting dogs in the home } \\
\text { context: } \\
\text { GoBone: a remote-controlled bone, that can be interactive, with the bone moving and offering playful } \\
\text { opportunities by phone https://www.kickstarter.com/projects/santiagogutierrez/gobone-all-day-play- } \\
\text { for-you-and-your-dog } \\
\text { Easyplay: treat release interactive camera ball https://www.youtube.com/watch?v=_DBjSK7EISo } \\
\text { Clever pet: game-based approach for dogs where treats are provided in response to pattern } \\
\text { following, based on the use of lit touch pad https://clever.pet/\#remodal--hero-video }\end{array}$ \\
\hline 8 & $\begin{array}{l}\text { Using } \\
\text { technology with } \\
\text { dogs }\end{array}$ & $\begin{array}{l}\text { Owners were asked if they would be interested in purchasing one of these toys and why / why not. } \\
\text { Owners were asked what kinds of technology might engage both them and the dog and what kind of } \\
\text { games that they played / interactions they had that might be supported by technology. }\end{array}$ \\
\hline
\end{tabular}

As Georgie's owner noted "she knows when I need her and knows that when she needs something, I'm here" One owner (Evra's) identified with Dotson and Hyatt's (2008)'s Anthropomorphic dimension viewing the dog more as a person than a dog. None of our owners identified as the third relationship dimension of having a dog-oriented self-concept, with dog both an extension of the self and the human's best friend.

All owners reported that their dogs sought playful interactions, with most owners reporting that their dogs actively sought play on a daily basis, including those towards the older end of the spectrum.

All of the dogs had a range of approaches to engaging with their owners. Typically, when dogs wanted their owners to provide a quickly required, important, often utilitarian task, they used their most effective mechanism of barking at the owner, for example Bentley's owner commented "if he barks at me he generally needs a pee." Dogs also used other sound signals, for example, Jemma "hits the door with her paw, making it clear I know she wants out." Georgie's owner noted "when her water's finished, she holds her bowl with her paw and spins it so it makes a noise, if she wants more."

With dogs highly motivated by food, a number of behaviours relate directly to the goal of getting more. Red and Murphy's owners noted "they are planning all the time, can they get on the table? is there any food on the bench? Has someone left the bin open?"
The interest in food frequently involves following behaviour, where the dog trails the owner, for example with Rupert, "he follows my wife because she's a soft touch for treats." Whiskey's (see Figure 1) owner noted "he follows me around all day. Sometimes I think for company but he always appears in the kitchen so probably food." Some dogs didn't follow, but were paying attention to food potential, for example Georgie's owner noted "she's lying in front of the fire apparently asleep, but the minute she hears the snip of the scissors for her ham, she's there with her tongue hanging out."

However, far more common than commands for action or attempts to initiate play are behaviours targeting physical interaction. This generally involves a gentle instigation, with dogs nudging and gently suggesting to their owners that interaction is required. All of the dogs in our study wanted to be companions, they wanted to be with their owners, for example, to access affection through stroking, Whiskey's owner noted "he likes to be made a fuss of and loves being stroked." Quite why physical interaction such as stroking and petting is desired by dogs is unclear, it doesn't replicate dog-dog behaviour, with licking typically of short duration, rather than the slow strokes typical of many dogowner interactions. However, for whatever reason and the literature doesn't know why, dogs enjoy affectionate petting from their owner. All of the dogs in our study sought interactions that demonstrated 
affection and companionship, similarly some of our owners owned dogs for those reasons, for example, Bentleys owner commented "we like a cuddle; it's why you have a dog isn't it, the unconditional love and affection." And clearly, the dogs feel the same, for example, Rupert's owner commented "he thinks he's a Chihuahua and will get on my wife's lap for kisses despite being 4 stone in weight." This is clearly a dyadic view, for example Evra's owner noted that "we like to snuggle on the couch" and throughout it is this sense of we, the dog-owner dyad, not the dog nor the owner themselves, that underpins this affective interaction.

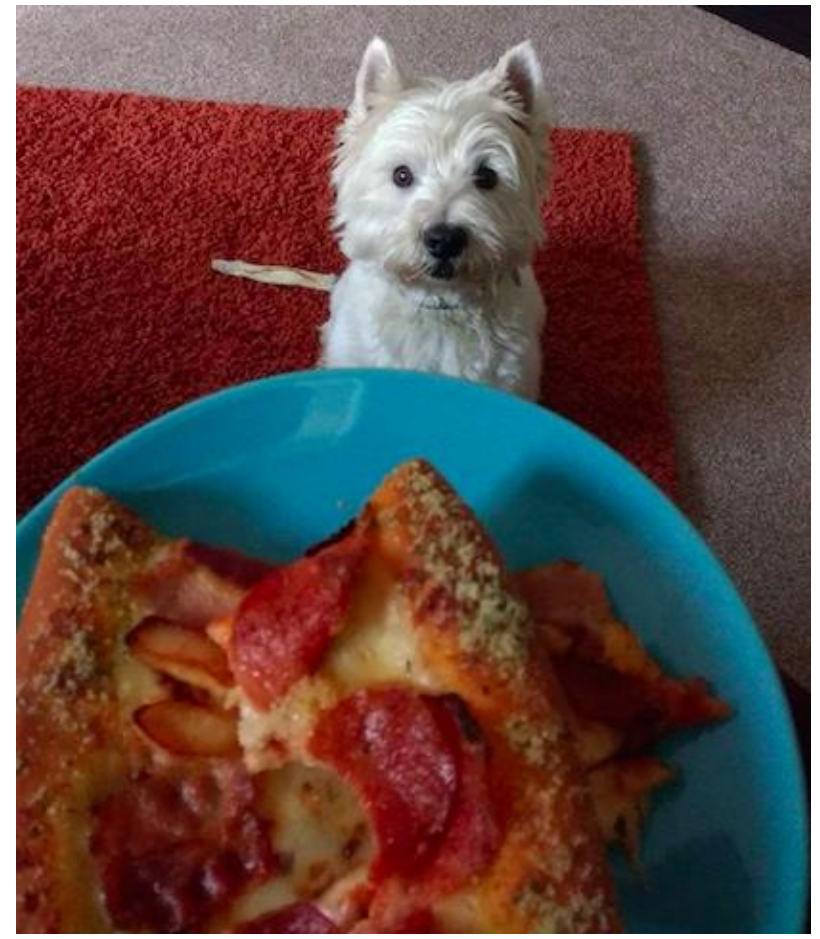

Figure 1: Whiskey showing interest in food

\subsection{Dog Toys and Instigating Play Interactions}

This section draws insights from theme 2 (Motivations), theme 3 (Interactions and Play) and theme 4 (Dog toys).

All of the owners had over time purchased toys of different descriptions for their dogs. Most dogs appear to have a preferred type of toy, rather than a specific favoured plaything. This included plush toys, such as Red and Murphy's (sighthounds) "small furry animals," Georgie's (Cairn Terrier) "polar bears as big as her," Evra's squeaky toys; and Bentley's tug rope. In addition, some dogs love getting new toys, for example Red and Murphy "mob our friend when she comes in, she brings them new toys, and they love new toys." Some dogs, for example, Jemma, the Chow, didn't play with toys, "somewhat confused as to what toys are for as it doesn't involve food" whilst other dogs such as the Papillons "were not encouraged to play with toys," however, all of these dogs engage in playful interactions with their owners.

Somewhat surprisingly, in the main, toys were only of interest to the dogs when used in joint play with their owner. When asked about solo play with the toys, owners reported that, as their dogs left puppyhood and became adults, they showed little interest in engaging with toys for their own amusement. Indeed, the amusement value that toys generated appeared only to relate to the extent to which the toys generated interest from the owners. Toby's owner commented "he will pick the toy up but only as a way to get my attention; if I'm busy and don't respond he shelves the idea and will go back to sleep." Where, more than one dog lived together, toys were sometimes used in dog-only play, for example Red and Murphy's owner stated: "they have a complicated game of stealing, hiding and finding their toys without involving us at all"

All owners agreed that the dogs were more interested in solo toy play as puppies and young dogs. In the session, Elwyn, the 6 month old Papillon, played with anything he could find, from toys to household objects to everyone present including the dogs he lived with. However, for most owners, toy use in puppyhood generally revolved around combating a behavioural habit. Evra's owner summed this up: "when he was teething he would chew anything; skirting boards, handbags and he used to spend a lot of time with a rubber bone but now he's not interested."

Actively seeking interaction with owners was seen through the initiation of play, with a range of techniques used to motivate the owner into playing and interacting with the dog. Typical approaches ranged from the dog presenting toys to the owners, nudging the owner for attention and barking.

If their first attempt to gain attention and play failed some dogs would up-the-ante, so to speak, in order to gain attention. Rupert's (see Figure 2) owner commented "he seems to place a value on things that he shouldn't have - my things. If he doesn't get attention he will go off and find something like a TV Remote." Georgie's owner noted "if I don't do what she wants, first it's a nudge, then an example of how to play with some fun growling and then a few sharp barks to tell me to hurry up."

Whilst dogs instigate play with their owners this is not necessarily reciprocal. In 3 households, the owners did not instigate play although they did engage in training their dogs, for example, Jemma's owner noted "she's not playful, but enjoys learning tricks... although there has to be treats involved." The Papillons' owner commented 'they play with each other and I focus on training, that way we're all happy." 


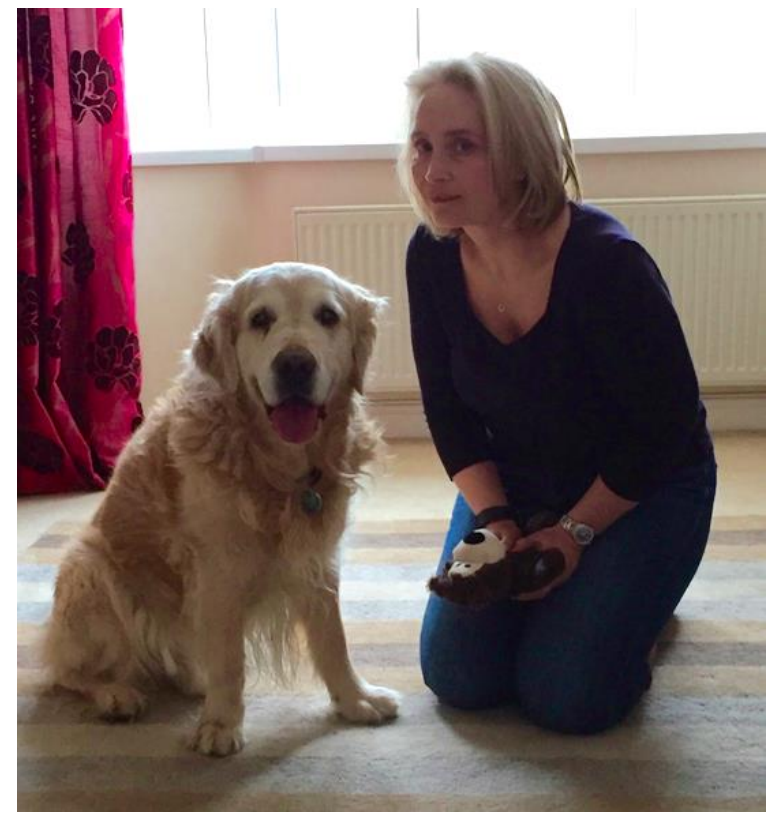

Figure 2: Rupert and his owner ready to play

\subsection{Dog and Owner Shared Games}

This section draws insights from interview theme 2 (motivations) and theme 3 (Interactions and Play).

Reported games included the typical activities one might expect with the most popular games being Tug with a variety of different toys and objects; retrieving objects and catching objects. In some households, with dogs with playful owners, games are created, for example, Bentley's owner described a typical game: "I leave him in the hall and then run into the living room and hide behind the curtain or somewhere if he doesn't find me straight away I jump out on him and he gets very excited." Owners instigated games such as with Whiskey, the West Highland White terrier who enjoyed "chasing his owner round the table in between long periods of sleep."

An owner-instigated game that was played in a number of households was Hide and Seek, with food as the hidden object. This game was sometimes played collocated, for example Rupert "loves the Gofindey Game. We plant biscuits all around the house and he will happily spend half an hour looking for them." Meanwhile, other households use hide and seek to occupy the dog as their owner departs, with Jemma "left happily and purposefully searching."

Play was ubiquitously viewed by owners as a way to bond, an affective experience that underpinned their ongoing companionship with their dogs. When asked what would characterise a good play experience a common theme related to the experience building a bond and affection. Whiskey's owner commented "just bonding; spending time with him." Rupert's owner highlighted this facet while reinforcing the need for exercise "play needs to be fun and tiring because he has a lot of energy but it's also filled with shared affection." Toby's owner highlighted affection as a key motivator for play on both parts but due to Toby's health didn't want to over-stimulate him: "we love interaction which always ends in a cuddle but I have to be careful not to get him too excited as he's not had the best of health."

With less playful dogs, owners highlighted that dogs wanted to be attended to, to be stroked and petted, in some ways a gentle kind of play or the affective results of play without the need to play. For example, during the session Red and Murphy who according to their owners "always have a plan" slowly but surely interacted and drew their owners from kitchen to sofa and being comfortably together.

\subsection{Dogs, Sounds and Audio-Visual Technology}

This section draws insights from interview theme 5 (Voices and sounds) and theme 6 (Audio-visual). Half of our dogs showed an occasional interest in the TV, with the other half not interested at all. Bentley's owner routinely left the TV on for him when he was alone: "I leave the TV on all day so that he has company; we always have the TV on when we are in so it's more normal for him". Although Whiskey showed no interest in the TV, his owner confessed that she would leave the radio on for him when she's not home but could not articulate a reason for doing this and was amused by her own behaviour.

When dogs showed interest in the TV this tended to be when animals could either be seen or heard but interest was generally fleeting. Evra's owner commented: "he's responded once or twice by trying to sniff the screen but he loses interest." Georgie's owner noted "she runs up to the TV and barks particularly if there is a dog barking or running."

Some owners had recorded their dogs, both Evra and Rupert's owners regularly made videos of their dogs and noted that they would respond on playback to what they could hear.

\subsection{Responding to Dog Technology}

This section draws insights from theme 2 (Motivations), theme 7 (Technology for dogs) and theme 8 (Using technology with dogs). We showed our owners the promotional videos for three existing digital technology toys for dogs, all of which were targeted at supporting remote engagement. Table 2 summarises the perceived positive and negative responses to these toys in relation to their own dogs and contexts.

To an extent, all of our owners considered the toys to be boredom busters and to be used in place of human-dog interaction when the owner was at work. All three promotional videos focus use this premise in their advertising and therefore focus on dog solo 
play with the toy. Our owner's reactions to this were negative, in the main, and related to their own feelings about leaving pets home alone for extended periods.

\subsubsection{Dog-Tech for Play}

Many owners believed that because their dogs showed little interest in solo play with their current toys that their interests in the technology enabled devices would also be limited and confined to the length of period that treats were available. Evra's owner commented "I have to leave him while I'm at work so would love something like this, if it worked, but I think as soon as he'd eaten the treats he'd lose interest". Toby's owner colourfully highlighted that the treat compartment wouldn't necessarily work for larger dogs "for a big boy like Toby treats that size would be like feeding an elephant a cherry!' Rupert's owner commented that "Our Go-findey game is considerably cheaper and would keep him occupied longer. He always seems very pleased with himself doing that - he would crunch these toys the way he gets treats from a stuffed Kong." The sighthounds owners were concerned that the remote toys "would over stimulate them" and be wholly inappropriate for dogs left alone, they also mentioned that their dogs "get great pleasure from a 50 pence furry mouse from the charity shop... you could buy a lifetime of furry toys that would cost less than something they would have little interest in."

\subsubsection{Remote Controlled Dog Tech}

Considering the ability to control the toys was appealing for those owners who had to leave their dogs. for example, when they were at work. In gaining the dog's attention remotely all indicated that movement was usually a good way at attracting the dog. Bentley's owner believed that movement would attract his attention "He reacts to movement so it would be more interesting than a standard toy". Rupert's owner believed movement would work but not in a ball or bone shape. "Bear's a small game hunter; he'd chase a spider all day but a ball or plastic bone is boring. I think the shape and movement characteristics would need to be more animal-like or at least less predictable". This view was supported by Evra's owner when reflecting on her childhood pet: Poppy, a West Highland Terrier. "Poppy was playful and would chase things. When I was little we tied some string round a ball and hide behind the settee and moved the ball past her. She wasn't bothered but when we did it with paper she pounced. Might have been the shape or noise maybe".

One toy GoBone was illustrated being used with the owners present. The majority (all bar two) could not see the point of this. Toby's owner said: "why would I want to use remote control; just get on the floor with the dog". Whiskey's owner really liked the distance control because it would allow her adult children who now live away from home to still interact with Whiskey and also it would enable her husband who as a fear of dogs to play with him. "We bought whiskey because the kids wanted a dog but John has always been fearful of dogs. He will walk whiskey and he will pat his head but he'd never play with him and he misses out on a lot of fun". She went on to the suggest the technology could be used by people with mobility problems to engage in play activity with their pets. In Georgie's home, whilst the adults were unconvinced, the teenager was more interested and thought that it would be fun "she enjoys chasing things and you could do it without her knowing it was you."

\subsubsection{Dog Camera Technologies}

All owners interviewed liked the prospect of keeping an eye on their dog when they weren't home. Georgie's teenager was doubtful as to how interesting this would be, suggesting "it would be better if she had a camera on so we could see what she sees, rather than watching her sleep on the settee

Table 2: Reactions to existing technology

\begin{tabular}{|l|l|l|l|}
\hline & \multicolumn{1}{|c|}{ Go Bone } & \multicolumn{1}{c|}{ Clever Pet } \\
\hline & & & \\
\hline Positive & $\begin{array}{l}\text { Movement, Nodules, } \\
\text { Rubber; Distance control } \\
\text { For people who can't or } \\
\text { don't want physical } \\
\text { contact }\end{array}$ & $\begin{array}{l}\text { Keeping an eye on him } \\
\text { Distributed family could } \\
\text { interact with him } \\
\text { For people who can't or } \\
\text { don't want physical contact }\end{array}$ & $\begin{array}{l}\text { Like the idea of mental stimulation } \\
\text { Would keep dog occupied longer } \\
\text { Good for puppies }\end{array}$ \\
\hline Negative & $\begin{array}{l}\text { Small treat chamber } \\
\text { Doesn't like hard toys } \\
\text { Expensive }\end{array}$ & $\begin{array}{l}\text { Two-way voice interaction } \\
\text { Small treat chamber } \\
\text { Expensive }\end{array}$ & $\begin{array}{l}\text { Need for training } \\
\text { Not for old dogs } \\
\text { Expensive }\end{array}$ \\
\hline
\end{tabular}




\subsubsection{Remote Conversations with Dogs}

Although all owners were keen on watching the dog, the idea of being able to speak to the dog from a distance was less popular. Some owners doubted whether this would work, for example, Jemma's owner commented "she wouldn't know what it was, and unless it quickly involved food, would not be interested." Several owners, including the Papillons' Whiskey's and Red and Murphy's did not believe their dog would react to a disembodied voice.

Although Whiskey's owner doubted Whiskey would respond to the voice, she was also concerned that it might cause distress in other dogs. Other owners were also disturbed by this, for example, Bentley's owner hated the feature and said: "That's cruel, why would you tease a dog like that? It's rotten!". Rupert's owner said: "If my wife phones when she is out and he hears her voice he becomes frantic. This could really upset him."

\subsubsection{Thinking Technologies}

Most owners were positive about technology that stimulated the dog to think, such as Clever Pet. Most thought that it would be better introduced with young dogs who are able to learn, however, Jemma's owner disagreed "she can do more now and enjoys learning new tricks." Some weren't positive about their belief in their dog's ability to solve puzzles. Toby's owner said "He's too thick for that". Rupert's owner was more positive: "he's quite clever and my wife did a lot of training with him and I think he might have taken to that but maybe too old now". There appeared to be a trade-off in terms of how much effort the toy would require from owners. Bentley's owner said: "I've never trained any of my dogs, l've not got the patience. If he could teach himself or learn by accident, then fine".

\subsection{Ideas for Dogs and Technology}

We asked owners for their thoughts on how technology might be used to augment their current play activities with their dogs (theme 8).

Two owners: Bentley and Rupert's suggested that technology either through phones or via devices such as Amazon Echo could be used to enhance their hide and seek games. Bentley's owner commented: If you could have my voice or sounds he liked coming from me and somewhere else in the house then that might be fun during hide and go seek. Sound was a theme that was raised by other owners as an opportunity that might be leveraged within games. Owners also highlighted that when they showed interest in an object their dogs would become interested suggesting that a toy that might first engage the owners interest might serve to stimulate the dogs'. Although the Papillon's owner was not interested in play, she felt that there was "enormous potential for using technology to train dogs particularly as immediate feedback can be given."

During the discussion, in addition to technologies for play, a number of situations where technology could be of benefit emerged, although the owners were not really aware that the technology existed for such challenges. For example, Red's owner was interested in the GPS tracker after commenting "he can just head off across the moor sometimes. You can't see him and it is so worrying, waiting for him to come back." Georgie's and Jemma's owners both mentioned how useful some sort of "technology opened dog flap" would be.'

\section{KEY FINDINGS AND INTERPRETATION}

Dogs want to engage with their owners, they seek to create opportunities that involve interactions, from reciprocal affection to play. Whilst all of the dogs sometimes initiated playful interactions, not all owners instigated play with their dogs. However, owners who were not playful, typically replaced this with other activities, such as training or lounging about together.

Although all of the owners had purchased dog toys for their dogs, from the lack of interest in solo play with these toys, it could be suggested that dog toys are not really a play item for the dog. Instead, from our results it can be seen that the toy is a device used by the dog to support interaction with their owners. In some ways, current dog toys should be rebranded as owner-dog toys, toys that meet the dog's requirements for playing with humans. Such toys make use of our potential to tug and to throw, and our ability to understand the game.

Dogs use a variety of approaches to initiate playful interactions with their owners. However, if the play isn't really for the dog, which it would be if the dog played alone, then who is the play for and what is the dog's strategy in initiating play? Although all owners agreed that their dogs were strongly motivated by food, it became clear that dogs can be highly motivated for non-food related aims. This motivation is related to affirming companionship, with the point of play appearing to be the dog and owner exhibiting positive affect. This outcome rather than the toy or play is the dog's intention, perhaps to gain this sense of bonding and affection or perhaps, just to help their owner be happier.

Our owners were not particularly convinced by the dog technologies that they were shown, with all of the products considered to be high-cost for relatively limited functionality. The majority of remote engagement technology for dogs is based on treats, however, our owners felt that without the incentive of treats (or once the treats were gone), the dog-tech toys (like the dog's other toys) would go unplayed with and ignored. 
Owners agreed that movement was a good way to attract a dog and that in this way, the technology offered more than a standard toy. Owners noted that technology toys could look and move differently from standard toys for example simulating prey movement patterns.

All owners were interested in technology that enabled them to watch the dog. However, this technology is clearly only for the owner, the dog does not know it is being watched by a remote person. However, whilst surveilling the dog was viewed as positive, in general, owners were somewhat unconvinced about remotely engaging with their dog by voice. Several owners thought that their dog wouldn't respond, whilst others felt that it might upset the dog. This is a somewhat surprising result as a key selling point for many of the remote toys was this advantage of the dog being able to hear their owner remotely.

\section{DISCUSSION}

This work is part of the FIDO (Fun Interactions for Dogs and their Owners) project that explores the potential of technology to enhance dog-human companionship. In this initial study reported here, we were aiming to gain insights into how technology might be used to enhance the dog-owner context, particularly when the dog and their owner are collocated in the home.

There is clearly an interest and a ready market for buying technology for dogs, however, the focus on remote rather than collocated experiences has most typically resulted in sophisticated treat dispensers for the remote owner rather than the provision of a meaningful or playful context together. From an owner perspective we can understand that cameras, treat dispensers or toys might resolve the challenge of leaving the dog home alone. In reality this probably does very little for the dog, whilst somewhat salving the conscience of the owner. In using current dog technologies, whilst owners may feel they are engaging in remote play or some sort of meaningful interaction via technology, it is unlikely that this is how the dog views the experience.

For the dog, play with their owners is different to other sorts of play, either solo or with other dogs. This is substantiated in the literature, for example (Rooney, Bradshaw, \& Robinson, 2000) highlighted the structure of dog-human object-oriented play differs to its dog counterpart. This includes a decrease in competitive play (e.g. less motivation to possess the object with a human player than with another dog) and an increase in interactive behaviours (e.g. chase, fetch) rather than solitary play (e.g. chew, hold). Rooney hypothesises that dogs are aware of the players (as non-dogs) and the playful context of the interaction. The results from our study support this view that dogs are context- aware, and further, that the dogs are proactively engaging in creating a playful context.

In instigating play, dogs are seeking to engage in reciprocal interaction with their companion, using their toys in their communication strategies to initiate engagement with their owner. Notably, this strategy differs dependant on who the dog is interacting with, with the dog tailoring their opening gambit accordingly. Thus, in the design of technologies for dogs and owners, we need to consider how we can support and promote positive affect and relationship affirmation.

Although none of our participants had considered buying dog technology, the opportunity to watch, locate and let out the dog technologically was of interest to some. Of these, only the 'dog-flap' is dogcentred, with cameras and trackers instead for the owners, either for entertainment or peace of mind.

In our study, we showed the participants clips of remote toys. Responses were primarily negative, but with the focus on the inappropriateness of leaving the dog alone, rather than of the toys per se. However, whilst some benefits could be seen, in general, our participants were unconvinced by the price and the ongoing interest of their dogs in the remote toys.

In designing technology for dogs it is likely that combinations of visual, acoustic, gustatory, tactile, and olfactory interactions could contribute to an innovative, engaging dog-owner technology experience. However, for the moment we are still constrained by what can be available and within a price range that owners accept. Perhaps we could design technology for known dog characteristics. For example, most dogs are excited and interested in new toys, with (Pullen, Merrill, \& Bradshaw, 2012) noting that dogs "show intense but transient neophilia towards novel objects." However, on average after only five 30 second exposures of actual playtime with the toy the dogs lost interest. Creating a technology toy that was somehow 'new' every day could be possible, but somehow seems of dubious value for two and a half minutes of interest.

From our study, potential dog technology directions included game-based experience such as hide and seek leveraging owner voice recordings; physical toys that might serve to engage the owner initially but also serve to peek the dog's interests such as Fidget puzzles; and toys that might create positive, audible affect in owners.

Somewhat strangely our owners were keen on dogs being encouraged to think, although it is not really clear what this is based on. The sighthounds apparently plan and other dogs understand games such as hide and seek, thus can think about how to interrogate a space, however, do dogs really enjoy problems and puzzles? Or is it that humans are very 
aware that engaging in mentally stimulating activities is important for human brains and falsely attribute the same benefits for their dogs. In (Bensky, Gosling, \& Sinn, 2013)'s extensive review of dog studies, dogs are identified as having limited independent problem-solving skills, although keen to engage in collaborative problem solving. Yet, the games we appear to be creating with technology, focus not on collaborative problem solving but instead on the dog's ability to solve problems on their own. It is likely we need to rethink this.

Whilst Mancini and others have focused on the needs and requirements of dog as user, in designing dog technology, the results from our study suggest a different view is needed. Thus, rather than allocating the dog as the 'primary end user' it is the dyad of owner and dog that must be considered to achieve effective collocated experiences. For example, Coren (Coren, 2016) highlights that unwanted toys can regain the dog's interest if the owner increases their own interest in playing with the toy. The owner's engagement with the toy adds to the toy's 'value' to the dog and the dog is more likely to use the toy in encouraging play. Thus, a dog's favourite toy may instead be the favourite of the owner. In our study we also found that some dogs were interested in playing with items that were not playful but of value and interest to owners, thus resulting in the dog attracting their owner's attention.

In that our focus was collocated engagement in the home, our initial ideas had leant towards creating a dog tech toy, however, our results fail to support this as a valid direction. There has been speculative design for dog technology (Lawson et al., 2015), however, again this focused on the dog as user. Such speculation is perhaps in the wrong direction, perhaps rather than new things for dogs to experience, what is actually needed is some way for the dog to more easily communicate with their owners. Although this may sound fantastical, what we do know is that the dog is already trying to communicate with us using the toys (that we have bought and therefore must be interested in) as a dialogue opener. Use of an explicit artefact such as the toy is required, because, whilst the dogs learn and respond to human social cues, we find it far harder to reciprocate and learn their cues.

So, how could we achieve this, how could we know that the dog would like us to affirm their affective bond? How could we understand that the dog wants an affective interaction or to play without needing the toy or some other arbitrary token to communicate? Whilst understanding the dog's social signals is challenging, approaches and systems that understand, recognise and process human social signals (Burgoon, 2017) have been successfully developed. It seems likely that a variant of these could be applied to dogs. Developing our understanding of dog-owner behaviours using video-based machine learning is facilitated by the massive collection of dog videos eagerly produced (and consumed) by owners. And so, it seems it would be possible to create a system that could understand the dog's communicative intention. And if we had what would effectively be a dog reader, would dogs then want to play with toys?

\section{LIMITATIONS}

Our study has a number of limitations. Principle among these are the small sample size, and the demographic characteristics of our sample. Our respondents were, in the main, female and over 50 years of age. Although this is congruent with the findings of survey studies (PFMA, 2017; APPA, 2017), which suggest that the primary dog owner in the home context is typically female, we must acknowledge that the age of the owner, and their position with a familial context, may have an impact on the nature of the interactions between the dog and its human co-habitees.

However, a strength of the work is that the interviews were situated in the dogs' home environment with both parties, and their toys present. This necessitated the use of opportunity sampling, to safeguard the researchers, where know contacts were used initially and then through their onward social connections further participants were found.

\section{CONCLUSION}

Whilst there are an increasing number of technologies for owners to remotely engage with their dogs, there is very little consideration of using technologies to interact together. With the exception of some automated fetch-object technologies, the dog's reward or motivation to engage with the technology substituting human engagement, is typically food. However, as our study highlights for many dogs as pets, their motivation to engage with their owner relates to much more than being a source of food. Rather than approaching the design of dog technology to solve our problem: that of worrying about our dog being alone at home, instead we suggest that the greater challenge is how technology could foster collocated play and affective experiences that serve to affirm our relationship as companions. Further research on the dog-owner dyad is needed, with considerable potential of technology that requires further study.

\section{ACKNOWLDEGEMENTS}

This work was partially supported by the AHRC funded Creative Fuse North East project.

We would like to thank our dogs and owners for participating in this research. 


\section{REFERENCES}

Adams, S. (2016). How PlayDate Used Indiegogo To Raise $\$ 580,000$ And Test A RemoteControlled Pet Toy. Forbes. Retrieved from https://www.forbes.com/sites/forbestreptalks/201 6/10/26/how-playdate-used-indiegogo-to-raise580000-and-test-a-remote-controlled-pet-toy/

APPA. (2017). Pet Industry Market Size \& Ownership Statistics. American Pet Products Association. Retrieved from http://www.americanpetproducts.org/press_indus trytrends.asp

Bensky, M. K., Gosling, S. D., \& Sinn, D. L. (2013). The World from a Dog's Point of View: A Review and Synthesis of Dog Cognition Research ScienceDirect. Advances in the Study of Behavior, 45, 209-406.

Beren, D. (2017). The 8 Best Pet Cameras to Buy in 2017. Retrieved 22 December 2017, from https://www.lifewire.com/best-pet-cameras4134642

Burgoon, J. K. (2017). Social Signal Processing. Cambridge UK: Cambridge University Press. Retrieved from https://www.cambridge.org/core/books/socialsignalprocessing/834565FD44AED8C4FB112A6A8DE 54318\#

CleverPet. (2018). CleverPet | Exercise your pet's mind + body. Retrieved 16 April 2018, from https://clever.pet/

Coren, S. (2016). Which Toys Do Dogs Prefer? Psychology Today. Retrieved from https://www.psychologytoday.com/us/blog/canin e-corner/201602/which-toys-do-dogs-prefer

DiGuilio, S. (2017). Pet Tech Will Transform a Dog's Life in Some Surprising Ways. NBC $\mathrm{MACH} \quad$ Newsletter. Retrieved from https://www.nbcnews.com/mach/technology/pettech-will-transform-dog-s-life-some-surprisingways-n764756

Dotson, M. J., \& Hyatt, E. M. (2008). Understanding dog-human companionship. Journal of Business Research, 61(5), 457-466. https://doi.org/10.1016/j.jbusres.2007.07.019

Findster Technologies. (2017). Findster GPS pet tracker. Retrieved 22 December 2017, from https://getfindster.com/

Fitbark. (2017). FitBark Dog Activity Monitor. Retrieved 22 December 2017, from https://www.fitbark.com/

Furbo. (2017). Furbo - World's Best Treat-Tossing Dog Camera - videos. Retrieved 22 December
2017 , from https://www.indiegogo.com/projects/1722469

GoBone. (2018). GoBone - All-day play for you and your dog. Retrieved 16 April 2018, from https://mygobone.com/

GroomArts Academy. (2018). UK Pet Market Industry Statistics. Retrieved 16 April 2018, from https://groomarts.com/student-advice/marketinginsights

iFetch. (2018). iFetch Pet Toy - Automatic Ball Launcher. Retrieved 16 April 2018, from https://goifetch.com/

Jackson, M. M., Zeagler, C., Valentin, G., Martin, A., Martin, V., Delawalla, A., ... Starner, T. (2013). FIDO - facilitating interactions for dogs with occupations: wearable dog-activated interfaces, 8.

Lawson, S., Kirman, B., Linehan, C., Feltwell, T., \& Hopkins, L. (2015). Problematising Upstream Technology Through Speculative Design: The Case of Quantified Cats and Dogs. In Proceedings of the 33rd Annual ACM Conference on Human Factors in Computing Systems (pp. 2663-2672). New York, NY, USA: ACM. https://doi.org/10.1145/2702123.2702260

Mancini, C. (2011). Animal-Computer Interaction (ACl): a Manifesto, 18(4), 69-73.

Mancini, C. (2017). Towards an animal-centred ethics for Animal-Computer Interaction ScienceDirect. International Journal of HumanComputer Studies, 98, 221-233.

McConnell, A. R., Brown, C. M., Shoda, T. M., Martin, C. M., \& Stayton, L. E. (2011). Friends with benefits: On the positive consequences of pet ownership [Data set]. https://doi.org/10.1037/e683152011-002

Paldanius, M., Kärkkäinen, T., Väänänen-VainioMattila, K., Juhlin, O., \& Häkkilä, J. (2011). Communication Technology for Human-dog Interaction: Exploration of Dog Owners' Experiences and Expectations. In Proceedings of the SIGCHI Conference on Human Factors in Computing Systems (pp. 2641-2650). New York, NY, USA: ACM. https://doi.org/10.1145/1978942.1979329

Pawbo. (2017). Pawbo. Retrieved 22 December 2017, from https://www.pawbo.com/uk/

Petcube. (2017). Petcube Wi-Fi Pet Cameras Monitor \& Interact With Pets Remotely. Retrieved 22 December 2017, from https://petcube.com/

Petzi. (2016). Petzi Treat Cam - WiFi Pet Camera \& Treat Dispenser. Retrieved from https://www.youtube.com/watch?v=BAOYO_2Mr 84 
PFMA. (2017). Pet Population 2017. Pet Food Manufacturer's Association. Retrieved from https://www.pfma.org.uk/pet-population-2017

PlayDate. (2017). PlayDate: World's First Pet Camera in a Smart Ball. Retrieved 22 December 2017, https://www.indiegogo.com/projects/1711382

Pullen, A. J., Merrill, R. J. N., \& Bradshaw, J. W. S. (2012). Habituation and dishabituation during object play in kennel-housed dogs. Animal Cognition, 15(6), 1143-1150. https://doi.org/10.1007/s10071-012-0538-2

Robinson, C. L., Mancini, C., van der Linden, J., Guest, C., \& Harris, R. (2014). Canine-centered Interface Design: Supporting the Work of Diabetes Alert Dogs. In Proceedings of the SIGCHI Conference on Human Factors in Computing Systems (pp. 3757-3766). New York, NY, USA: ACM. https://doi.org/10.1145/2556288.2557396
Rooney, N. J., Bradshaw, J. W. S., \& Robinson, I. H. (2000). A comparison of dog-dog and doghuman play behaviour. Applied Animal Behaviour Science, 66(3), 235-248. https://doi.org/10.1016/S0168-1591(99)00078-7

Technavio. (2017). Global Pet Wearable Market 2016-2020 -. Market Research Reports Industry Analysis Size \& Trends. Retrieved from https://www.technavio.com/report/globalmachine-machine-m2m-and-connected-devicesglobal-pet-wearable-market-2016-20200?utm_source $=$ T4\&utm_campaign=Media\&utm medium $=B W$

Tractive. (2017). Tractive GPS Pet Tracker. Retrieved 22 December 2017, from https://tractive.com/uk_en/pd/gps-tracker

Whistle. (2017). Whistle GPS Pet Tracker. Retrieved 22 December 2017, from https://www.whistle.com/ 